\title{
Examples of sex/gender sensitivity in epidemiological research: results of an evaluation of original articles published in JECH 2006-2014
}

Ingeborg Jahn ${ }^{1 *}$, Claudia Börnhorst ${ }^{2}$, Frauke Günther ${ }^{2}$ and Tilman Brand ${ }^{1}$

\begin{abstract}
Background: During the last decades, sex and gender biases have been identified in various areas of biomedical and public health research, leading to compromised validity of research findings. As a response, methodological requirements were developed but these are rarely translated into research practice. The aim of this study is to provide good practice examples of sex/gender sensitive health research.

Methods: We conducted a systematic search of research articles published in JECH between 2006 and 2014. An instrument was constructed to evaluate sex/gender sensitivity in four stages of the research process (background, study design, statistical analysis, discussion).

Results: In total, 37 articles covering diverse topics were included. Thereof, 22 were evaluated as good practice example in at least one stage; two articles achieved highest ratings across all stages. Good examples of the background referred to available knowledge on sex/gender differences and sex/gender informed theoretical frameworks. Related to the study design, good examples calculated sample sizes to be able to detect sex/gender differences, selected sex/gender sensitive outcome/exposure indicators, or chose different cut-off values for male and female participants. Good examples of statistical analyses used interaction terms with sex/gender or different shapes of the estimated relationship for men and women. Examples of good discussions interpreted their findings related to social and biological explanatory models or questioned the statistical methods used to detect sex/gender differences.

Conclusions: The identified good practice examples may inspire researchers to critically reflect on the relevance of sex/gender issues of their studies and help them to translate methodological recommendations of sex/gender sensitivity into research practice.
\end{abstract}

Keywords: Epidemiological methods, Sex/gender-based analysis, Good practice example

\section{Background}

During the last three decades, sex and gender biases have been identified in biomedical and public health research [1-3]. Stephenson and McKee wrote, in 1993, that in epidemiology " $[g]$ ender is nearly always treated as a potential confounding variable, the effects of which, if there are any, must be controlled for statistically and

\footnotetext{
* Correspondence: jahn@leibniz-bips.de

'Department Prevention and Evaluation, Leibniz Institute for Prevention Research and Epidemiology - BIPS, Achterstr. 30, 28359 Bremen, Germany Full list of author information is available at the end of the article
}

then ignored. Gender differences in health per se are seldom given a second glance" [4]. Although some progress has been made, this statement still holds true for large parts of epidemiological research [5-7].

Sex and gender bias refers to an inadequate representation of men and women in study samples, in research teams, or responsible research positions, as recipients of research funding or as authors of publications $[8,9]$. In a broader sense, a comprehensive analysis of biological and social factors associated with being a man or a woman is postulated (sex- and gender-based analysis 
[10]) to explain or prevent sex- and gender-related health inequalities. Sex and gender bias impinges on the quality of epidemiologic research as it compromises the validity of research findings, leading to inaccurate conclusions about how women (or men) respond to a disease and inadequate treatment decisions [9]. From a feminist social science perspective, Eichler proposed four types of gender bias [11, 12], namely gender insensitivity (ignoring gender aspects), over-generalisation (generalisation of research results to a group that has not been studied), double standard (e.g. by drawing on gender stereotypes for explaining gender differences), and androcentrism (male as the norm). Beery and Zucker [1] used the term 'sex bias' referring to both inappropriate representation of men and women and neglected differences in biological mechanisms between males and females. Overall, evidence from different research fields suggests that sex and gender bias leads to gaps in the knowledge base and inequalities in the provision of healthcare - in many cases to the disadvantage of women $[13,14]$.

A central element of sex/gender sensitive research is the distinction between sex and gender. Although the terms 'sex' and 'gender' denote different aspects of being male and female, they are often used interchangeably in the literature [15-19]. Sex refers to biological characteristics such as chromosomes, hormones or reproductive organs commonly associated with being male or female. Gender refers to sociocultural attributes and related expositions commonly associated with being a man or a woman, such as personality traits, socially constructed roles, access to the labour market, or relative power [17]. However, scholars have warned that the sex-gender dichotomy may mask the complexity, interaction and entanglement between the two concepts [20-22]. To avoid simple dualisms between men and women, other scholars have drawn the attention to the within-group variations at the intersections of sex/gender with other social categories, such as socioeconomic position, race/ ethnicity, or age [23, 24]. Krieger [25] pointed out that clear conceptual models are needed for considering sex and gender, simultaneously, and their interrelations ('biologic expressions of gender,' 'gendered expression of biology'), "Yet, we do not live as a 'gendered' person one day and a 'sexed' organism the next; we are both, simultaneously, and for any given health outcome, it is an empirical question, not a philosophical principle, as to whether diverse permutations of gender and sex matteror are irrelevant." For this purpose, a clear understanding of sex and gender as distinct but entangled concepts and consistent usage of terms are basic requirements of sex/gender sensitive epidemiology [22, 23, 25, 26].

In accordance with other authors [18, 22, 26-30], we prefer to use the shortened version 'sex/gender' in this article instead of 'sex and gender' or 'sex and/or gender'.
By using the slashed version we want to indicate that sex and gender are distinct concepts, while the slash stands for the potential interrelations between biological and sociocultural aspects of being a man, a woman, or a sex/gender diverse person.

To reduce sex/gender bias, concepts such as 'engendering epidemiology' [31] or 'gendered epidemiology' [24] were proposed and methodological requirements for sex/ gender sensitive epidemiological research were developed [13, 22-24, 32-37]. However, these concepts are rarely translated into research practice [23, 24, 32-35, 37]. Yet, paying attention to sex/gender-related aspects has also been implemented as a requirement in research funding schemes as of the European Union [38] and in science publishing [39]. Thus, applying sex/gender sensitive methods is of increasing relevance for health researchers and epidemiologists [34, 36, 37]. In order to increase sex/ gender sensitivity of epidemiological research, it might be useful to present good practice examples of sex/gender sensitive health research. We defined good practice examples as sections of published academic articles that have successfully met methodological requirements of sex/gender sensitivity or that have explicitly described sex/genderrelated research practices. Good practice examples can inspire researchers aiming to increase sex/gender sensitivity of their studies and help them to translate methodological recommendations of sex/gender sensitivity into research practice [15].

This study was part of the 'Epi goes Gender' project in Germany [36] and aimed to identify recent examples of good sex/gender sensitive research practice illustrating how to apply sex/gender sensitive principles in health research. To this end, we evaluated sex/gender-related research articles published in the Journal of Epidemiology and Community Health (JECH). We selected JECH as the basis for our search due to the journal's scope (social medicine, social epidemiology) and its major contributions to the field of sex/gender sensitive epidemiology, including the supplement entitled 'Engendering Epidemiology' in 2007 and further important publications in this field [13, 40-42].

\section{Methods}

\section{Search strategy}

To identify good practice examples of sex/gender sensitive research, we used the following search strategy. Inclusion criteria were (1) published in JECH between 2006 and 2014 to focus on recent development, (2) original research, and (3) title contains 'sex' or 'gender'. The rationale behind this search criterion was to increase the probability to discover articles explicitly dealing with sex/gender aspects [31]. Sex and gender were both included as search terms because we aimed to find examples for biological and sociocultural aspects - and their interrelations. Our 
aim was not to separate articles dealing with sex from those dealing with gender because, ideally, good practice examples consider both concepts. Articles were excluded if the term 'sex' did not denote being male or female or sex-related biological factors but was used in another meaning, e.g. sex(uality), sex work, sex ratio (of newborns). Furthermore, methodological, theoretical and political papers were excluded. The reason for this targeted scope of our search was that we did not aim to provide a comprehensive review of sex/gender sensitivity in epidemiological research, but to illustrate sex/gender sensitivity from purposefully selected examples. Overall, 73 papers were identified that included the terms 'sex' or 'gender' in their titles. Thereof, 37 articles met all inclusion criteria and were included in the evaluation (Table 1).

\section{Assessment instrument}

We constructed an instrument to evaluate the sex/gender sensitivity of the research presented in the selected articles (Fig. 1 and Additional file 1). Three basic assumptions of sex/gender sensitivity guided the development of the instrument, namely (1) sex/gender-related aspects should be reflected in all stages of the research process [33-35, 43], (2) a sound theoretical conceptualisation of sex/gender is necessary, including the complexity, interaction and entanglement between the two concepts as well as within group variations at the intersections of sex/gender with other social categories such as socioeconomic position, ethnicity or age $[23-25,42$, 44-46], and (3) appropriate analytic strategies are to be used $[47,48]$.

Although a clear distinction between sex and gender is important, our focus was more on how biological and sociocultural factors were included and less on the correct and consistent use of the terms sex and gender.

The evaluation of the full texts comprised three steps. In a first step, each main stage of the research process, represented by the sections of the article (background, study design, statistical analysis, discussion), was screened for addressing any sex/gender-related aspects. In a second step, specific attention was drawn to the operationalisation of sex/gender beyond the binary

Table 1 Number of identified, excluded and included papers

\begin{tabular}{ll}
\hline Journal of Epidemiology and Community Health & $\mathrm{N}$ \\
\hline Sex and/or gender [Title], 2006/01/01 - & 73 \\
2014/12/31 [Date - Publication] & \\
Excluded papers & 24 \\
- the title word 'sex' meant something & \\
other than the differentiation between & \\
males and females, women and men & \\
(e.g. sex ratio of offspring, sex work) & 12 \\
- methodological, theoretical, political papers & 37 \\
Included papers &
\end{tabular}

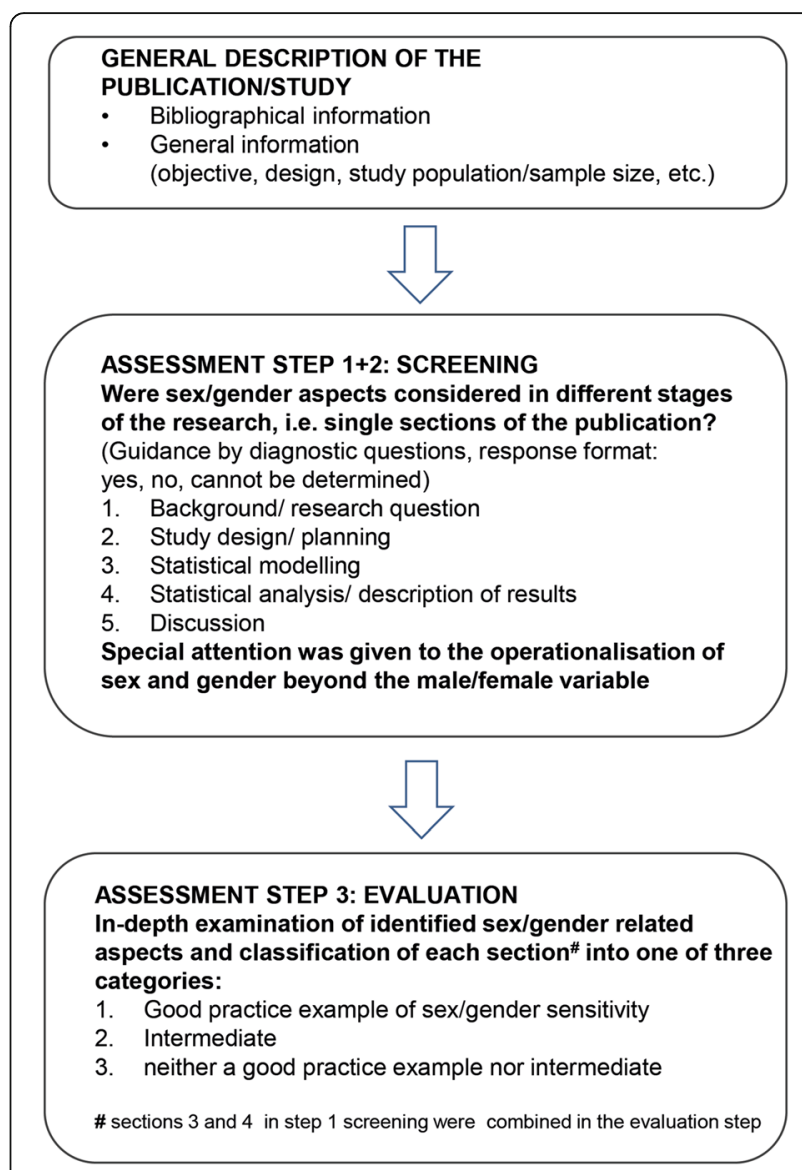

Fig. 1 Structure and content of the assessment instrument

male/female category. The third step included an indepth examination of the identified sex/gender-related aspects and a classification of each section into one of three categories: 'good practice example', 'intermediate', 'neither a good practice example nor intermediate'. Article sections were classified as 'good practice example' if it became apparent that sex/gender concepts guided the related stage of the research process. The category 'intermediate' was chosen if only some sex/gender aspects were addressed. The article sections were classified as 'neither a good practice example nor intermediate' if sex/gender differences or similarities were not addressed or addressed without any further justification, for example, the sole presentation of sex/gender stratified results. To guide the evaluation, the concept of diagnostic questions [43] was applied. The diagnostic questions were mainly derived based on Eichler et al. [43] and Hammarström [49]. Drafts of the assessment instrument were revised after consultation of experts qualified in epidemiology, public health and gender research. The final version was pretested in a multidisciplinary group of associates of the project 'Epi goes Gender' in 2012. The assessment instrument was a generic one and thus 
not specific to any field of epidemiologic research or study design. It should be highlighted that it was not our aim to assess the quality of the articles in terms of their contributions to their specific fields of research.

\section{Evaluation}

To achieve intersubjective validity, articles were independently evaluated by two evaluators. The first evaluation was completed by $\mathrm{CB}$ or FG, both biometricians and trained on the job in principles of sex/gender sensitive health research. The second evaluation was completed by IJ, a social scientist working in the field of sex/ gender sensitive health research as a senior researcher and principal investigator of the 'Epi goes Gender' project. The instrument was filled in based on the full text without considering any additional information such as design papers or supplementary material. In case of discordant evaluations, a consensus was achieved by communicative validation. In addition to the evaluation, contents of the good practice examples were extracted to illustrate how sex/gender sensitivity was achieved.

\section{Results}

We will first give a rough summary of the results and will then describe good practice examples identified for the different sections of the articles. The topics of the included articles were quite diverse as can be retrieved from article titles [50-86].

In 32 out of 37 articles, sex/gender-related aspects were explicitly named among the research aims, which can be grouped as follows: (1) investigation of the relationships between gender (inequalities) and health [50, $58,62,67,69,75]$; (2) analysis of sex and/or gender differences [51, 52, 54-56, 59, 66, 68, 70, 71, 78, 83, 86]; (3) effect modification analysis by sex/gender [53, 61, 76]; (4) investigation of sex/gender-based origins of health outcomes [57, 60, 63, 73, 77, 80, 81, 84, 85]; and (5) exploration of gender bias [82].

\section{Results of the screening (steps 1 and 2)}

Sex/gender aspects were addressed at least to some extent in 32 out of 37 background sections and in 31 out of 37 discussion sections. In the study design section, 19 out of 37 articles addressed sex/gender aspects. In all included articles, statistical analyses were adjusted for or stratified by sex/gender.

In the second step, we analysed whether sex and gender were operationalised beyond a binary male/female category, i.e. whether more than a single indicator for being male or female was used such as societal indicators of gender relations (e.g. gender equality index) or biological markers (e.g. hormone status). This was the case in 11 articles [51, 53, 58, 63, 66-71, 83] for gender and in 5 articles [54, 55, 60,62, 81] for both sex and gender. In 21 articles [50, 52, 56, 57, 59, 61, 64, 65, 72$80,82,84-86]$ sex/gender was operationalised as male/ female only.

\section{Results of the comprehensive assessment (step 3)}

Twenty-two out of 37 articles were rated as good practice example in at least one section and 2 articles achieved highest ratings across all four sections (Table 2).

In 14 out of 37 articles at least one section was classified as intermediate category. Only one article was rated as 'neither a good practice example nor intermediate' in each section. The proportion of good practice examples was highest for the background (17/37) and discussion $(14 / 37)$ sections. In the study design and the statistical analysis sections, 6 out of 37 and 5 out of 37 articles were identified as good practice examples, respectively.

\section{Background section}

All 17 good practice examples for this section referred to available knowledge on sex/gender differences. Some authors referred to gender-informed theoretical frameworks or explanatory models such as the multiple role model, role expansion theory [51, 67], homemaker hypotheses [61], gendered socialisation in cross-cultural comparisons [62], societal gender equality [66], or biological and social explanatory hypotheses for neonatal mortality [81]. The investigation of Heys et al. [60] was explicitly driven by biological differences leading to sex specific effects on lipids and fat patterning. Some authors critically reflected on the used research methods, e.g. averaging effect estimates across subgroups and thereby masking potential effect modifications [63, 68].

\section{Study design section}

Good practice examples for this section included the following elements: (1) selection of outcome variables that reflect sex/gender differences, (2) calculation of sample sizes enabling the detection of sex/gender differences, (3) selection of sex/gender sensitive exposure indicators, or (4) choosing specific cut-off values for exposure/outcome classifications for male and female participants. For example, Rosenstock et al. [81] applied sex- and gender-based operationalisations of the outcome variable and of influencing factors referring to the entanglement concept [22]. Heys et al. [60] selected the outcome variables based on biological mechanisms concerning the role of sex steroids and growth hormones during puberty. Ruiz-Cantero et al. [82] conducted a pilot study to obtain prevalences for their sample size calculation to attain sufficient statistical power for the detection of differences between men and women in the main study. Harryson et al. [58] as well as Mansdotter et al. [67] selected their exposure variable (work in the domestic and public sphere) based on concepts of gender equality and 
Table 2 Assessment of sex/gender sensitivity in each section of the selected articles - Synopsis of the results

\begin{tabular}{|c|c|c|c|c|}
\hline Reference & Background & $\begin{array}{l}\text { Study } \\
\text { design }\end{array}$ & $\begin{array}{l}\text { Statistical } \\
\text { analysis }\end{array}$ & Discussion \\
\hline 1. Bambra et al. [50] & ++ & + & $\circ$ & ++ \\
\hline 2. Berntsson et al. [51] & ++ & ++ & + & ++ \\
\hline $\begin{array}{l}\text { 3. Boone-Heinonen \& } \\
\text { Gordon-Larsen [52] }\end{array}$ & + & $\circ$ & + & + \\
\hline 4. Borrell et al. [53] & $\circ$ & $\circ$ & + & ++ \\
\hline 5. Escribà-Agüir et al. [54] & ++ & ++ & + & + \\
\hline $\begin{array}{l}\text { 6. Escribà-Agüir \& } \\
\text { Artazcoz [55] }\end{array}$ & ++ & ++ & + & + \\
\hline 7. Gissler et al. [56] & + & $\circ$ & $\circ$ & + \\
\hline 8. Haukenes et al. [57] & $\circ$ & $\circ$ & $\circ$ & + \\
\hline 9. Harryson et al. [58] & + & ++ & + & + \\
\hline $\begin{array}{l}\text { 10. Hernanadez \& } \\
\text { Pressler [59] }\end{array}$ & + & $\circ$ & + & + \\
\hline 11. Heys et al. [60] & ++ & ++ & + & $\circ$ \\
\hline 12. Hollander et al. [61] & ++ & $\circ$ & + & + \\
\hline 13. Ikeda et al. [62] & ++ & + & + & ++ \\
\hline 14. Kavanagh et al. [63] & ++ & + & ++ & ++ \\
\hline 15. King et al. [64] & $\circ$ & $\circ$ & $\circ$ & + \\
\hline 16. Kolarcik et al. [65] & $\circ$ & + & + & + \\
\hline $\begin{array}{l}\text { 17. Kovess-Masfety } \\
\text { et al. [66] }\end{array}$ & ++ & + & + & ++ \\
\hline 18. Mansdotter et al. [67] & ++ & ++ & ++ & ++ \\
\hline 19. Matheson et al. [68] & ++ & + & ++ & ++ \\
\hline 20. Matheson et al. [69] & ++ & + & ++ & + \\
\hline 21. Matheson et al. [70] & + & + & + & + \\
\hline 22. Matheson et al. [71] & + & + & $\circ$ & + \\
\hline 23. McCormack et al. [72] & + & $\circ$ & + & $\circ$ \\
\hline 24. Milner et al. [73] & + & $\circ$ & + & + \\
\hline 25. Mindell et al. [74] & $\circ$ & $\circ$ & $\circ$ & $\circ$ \\
\hline 26. Nante et al. [75] & ++ & + & + & ++ \\
\hline 27. Niclasen et al. [76] & + & $\circ$ & $\circ$ & $\circ$ \\
\hline 28. Pitel et al. [77] & + & $\circ$ & + & + \\
\hline 29. Ratner et al. [78] & + & + & + & + \\
\hline 30. Regidor et al. [79] & $\circ$ & $\circ$ & + & $\circ$ \\
\hline 31. Rigby \& Dorling [80] & $\circ$ & $\circ$ & $\circ$ & ++ \\
\hline 32. Rosenstock et al. [81] & ++ & ++ & ++ & ++ \\
\hline 33. Ruiz-Cantero et al. [82] & ++ & ++ & + & + \\
\hline 34. Staehelin et al. [83] & ++ & $\circ$ & $\circ$ & ++ \\
\hline 35. Strand et al. [84] & + & $\circ$ & + & ++ \\
\hline 36. Värnik et al. [85] & ++ & $\circ$ & $\circ$ & + \\
\hline $\begin{array}{l}\text { 37. Vigna-Taglianti } \\
\text { et al. [86] }\end{array}$ & + & $\circ$ & $\circ$ & ++ \\
\hline
\end{tabular}

Legend: $++=$ good practice examples of sex/gender sensitivity, $+=$ intermediate category (sex/gender aspects addressed to some extent); $\circ=$ neither a good practice example of sex/gender sensitivity nor intermediate category constructed a gender equality index. Escribà-Agüir et al. [54] and Escribà-Agüir and Artazcoz [55] used different cut off-values for men and women of the Edinburgh Postnatal Depression Scale as prior research had indicated that the threshold for men is two scale points lower compared to women.

\section{Statistical analysis section}

Good practice examples for this section explicitly accounted for sex/gender aspects in the statistical analyses. This included, for example, the derivation of specific measures accounting for sex/gender differences in exposure or outcome variables [67]. Models were not only stratified by or adjusted for the sex/gender variable (male/female), but further included, for example, interactions with biological or social factors to disentangle sex/gender differences [63, 81]. Conducting a sex/gender sensitive analysis could also mean that different models were fitted to unravel the effects of biological, social and environmental factors [68, 81]. In one example, the shape of the estimated relationship between alcohol consumption and neighbourhood deprivation was allowed to be non-linear and to vary between men and women [69].

\section{Discussion section}

Good practice examples for the discussion section provided interpretations of their findings by drawing on possible sex/gender-related explanatory approaches or theoretical models [51, 66-68, 81, 83]. Likewise, methodological issues were addressed [63, 67, 75]. For example, in their analysis of neighbourhood deprivation effects on health, Kavanagh et al. [63] critically reflected on the statistical methods used to detect differences between men and women and compared stratified analyses with analyses using statistical interactions. While stratified analyses separately assess the effects among women and men, statistical interactions indicate differences in the effects between women and men. This example highlights the clarity about the question whether effects of exposures in separated groups or differences of effect sizes across groups are to be determined that is needed for the definition of research questions and for subsequent statistical modelling.

\section{Discussion}

This study provides a collection of good practice examples of sex/gender sensitivity based on an evaluation of sex/gender-related health research in a selected scientific journal. Good practice examples were identified in four article sections/stages of the research process and in studies with different aims and designs. The results include examples for many methodological issues that have been discussed in the context of sex/gender sensitive research [23, 24, 32-34, 36, 37]. More good 
practice examples were found in the background and discussion sections than in the study design and statistical analysis sections. It is interesting to note that only one example (in two articles) was identified where different cut off-values for men and women were used $[54,55]$; one other example conducted a pilot study to obtain prevalences in males and females for a subsequent sample size calculation [82].

To the authors' knowledge this is the first study aiming to identify examples of good practice of sex/ gender sensitive research in epidemiology and thus providing practical ideas of sex/gender sensitivity for researchers based on existing science. The presentation of good practice examples demonstrates how sex/gender sensitivity can be accomplished. This may encourage researchers and reviewers to carefully reflect on their research and reviewing practice and could enhance the inclusion of sex/gender aspects in future research.

Our approach can be located in the context of the 'Gendered Innovations Framework' [46]. In accordance with this framework, our aim was to illustrate how concepts such as sex and gender can be integrated into the different stages of the research process [46]. The 'Gendered Innovations' website [87] offers information for sex/gender sensitive methodological principles in biomedical and public health research and has recently been adopted by the EU Horizon 2020 funding scheme [88]. Currently, 'Gendered Innovations' provides seven case studies from medicine and public health illustrating challenges of sex/gender sensitive research, such as the identification of relevant sex/gender factors and their interactions in colorectal cancer or a critical sex/ gender analysis of a dietary assessment using a food frequency questionnaire.

New guidelines to advance sex/gender reporting by the European Association of Science Editors are currently under way [39]. In this context 'sex and gender questions' were recently published [89], which can be used as a checklist when planning a study. There is a substantial overlap between these questions and the diagnostic questions we used in our assessment instrument. Furthermore, the questions emphasise that both the consideration or not of sex/gender aspects should be justified.

The research topics of the included articles were quite diverse. The evaluators' expertise covered several research fields but not all topics of the included articles. As a consequence our approach was a generic one, focusing on sex/ gender-related aspects but not evaluating the quality of the articles with respect to the state of the art in the specific research field. However, this generic approach enables us to demonstrate that high-quality sex/gender sensitive research can be conducted in a broad area of health research.
Based on the diagnostic questions of our assessment instrument and our findings in the evaluated articles, we developed a checklist of practical steps towards sex/gender sensitivity across the stages of the research process (Table 3). In the right column of Table 3 the steps are illustrated by examples from one research article that achieved high ratings across all four sections. The practical steps do not cover all aspects that have been discussed in the field of sex/gender sensitive research, but can also be used in combination with other concepts or guidelines [22, 39, 90-93].

Several measures were taken to establish intersubjective validity such as diagnostic questions to provide an orientation, double ratings and consensus building strategies. Nevertheless, the professional background of the evaluators may have had some influences on the assessment, for example, assigning the operationalisation of the variables to the statistical modelling part or to the study design. Searching for sex or gender in titles only may be viewed as a limited approach. However, comparing this strategy with an extended search including the abstracts of the articles revealed that the strategy was very successful in identifying studies that explicitly aim to investigate sex/gender-related aspects [94]. A further limitation could be that we did not examine supplementary materials or related papers of the included studies. These materials may have contained more information on aspects of the study design such as the validity of the measures and sample size calculations. However, our expectation was that the key elements of the study design would be published in the original article.

\section{Conclusion}

This study provides good practice examples of sex/ gender sensitivity in epidemiological research. The examples include different lines of research, such as questions of gender research in epidemiology, e.g. influences of individual or societal gender relations on health, as well as questions of the relevance of sex/ gender aspects for the definition of exposures, outcomes and respective pathways (sex/gender-based analysis). While gender research presupposes a specific epistemological perspective and research interest which may not be shared by many epidemiologists, sex/gender-based analysis is relevant to the quality of epidemiological research as it contributes to our understanding of causal pathways. Determining the relevance and well-founded inclusion or exclusion of sex/ gender aspects and the careful epidemiological analysis is an important requirement for a more equitable provision of healthcare and preferably gender transformative [95] preventative services for women and men. 
Table 3 Illustrated checklist of practical steps of sex/gender sensitivity in the stages of the research process

\begin{tabular}{l} 
Stage of research process - Practical steps \\
\hline 1. Background/Research question \\
1.1. Review of existing sex/gender-based knowledge - \\
Are there differences/similarities between and within \\
sex/gender groups? - What are the biological and social \\
causes? - Are there different results across time, \\
space or cultures?
\end{tabular}

1.2. Evaluation of the knowledge base. What is the sex/gender-related gap?

1.3. Formulation of sex/gender-related study aim and research question to address the knowledge gap

2. Study design

2.1 Definition of sex/gender-related biological and social factors based on a theoretical model

\subsection{Selection of sex/gender sensitive outcome and exposure measures}

2.3 Sample size calculation is justified with respect to sex/gender-related study aims, e.g. to detect differences between or within sex/gender groups

3. Statistical analysis

3.1 Analytic strategy, statistical modelling is justified with respect to the sex/gender-related aims of the study

3.2 The analysis is conducted stratified by sex/gender (if appropriate) but avoids overemphasis of sex/gender

3.3 Sex/gender stratified presentation of sample characteristics

3.4 Sex/gender differences and similarities are reported

\section{Discussion}

4.1 Findings are discussed in the context of existing literature; unexpected results, strength and weaknesses of the study with regard to sex/gender aspects are interpreted

4.2 Implications for research and practice of the main sex/gender-related findings are discussed
Example from [81]: Sex Differences in Neonatal Mortality in Sarlahi, Nepal: The Role of Biology and Environment

- Differences were found in the literature, e.g. between boys and girls in neonatal mortality in high-income countries (boys are at greater risk) and South Asia (sometimes girls experience more neonatal mortality), and in the early (days 1-7) and late (days 828) neonatal period - Biological explanations favouring survival of girls (height/weight, maturity of the lungs, sex steroid influences of the immune system), more relevant in high-income countries - Sociocultural explanations for girls' risk of neonatal mortality in South Asia: gender preference, differential care-seeking behaviours, birth order and family composition, perceptions of illnesses

"Unanswered questions remain regarding the impact that biological (immutable factors specific to the newborn or his/her mother) and environmental factors (mutable external factors) have on sex specific trends in neonatal mortality" [81]

"... biological and environmental factors that might explain sex differences in neonatal mortality..." [81]

- Biological factors typically indicating a higher risk for neonatal mortality in males: birth outcomes such as weight, gestational age, respiratory depression, malformations Social/environmental factors which may indicate a gender preference: peri- and postnatal care such as feeding practices, hygiene and skin care practices, warming practices and care-seeking behaviours

- Sex/gender-based justification of the outcome measure early/late neonatal mortality

- Secondary analysis of a population-based randomised trial, 23,662 newborns were included in the analysis

- Stratified analysis by sex/gender and ethnicity, explorative examination of sociodemographic, newborn and maternal characteristics; model building strategy reflected the four conditions: biological vs. social/environmental factors, early vs. late neonatal period

- Differentiation by ethnic groups (Pahadi and Madeshi)

- Sociodemographic characteristics are reported to not be meaningfully different between boys and girls

- Biological factor, care practices and crude mortality rates were presented by sex/ gender and differed significantly - Multivariate models analysing biological and social/ environmental factors in the early and the late neonatal period showed no influence of care related factors - Further exploration showed social factors in one ethnic group to be related with excess mortality in the late neonatal period
- Main results are discussed with regard to: • Expectations concerning early vs. late
neonatal period - Seasonal influences on food availability for pregnant women -
Newborn care services favoured boys, providing evidence of gender preference .
Differences within the group of girls depending on ethnic group (Pahadi, Madeshi)
and prior sex composition of siblings - Missing values on birth weight are discussed as
a limitation, but did not affect sex/gender-related factors
- Important issues are highlighted: (1) neonatal analysis must be stratified by early and
late period, (2) biology has a greater impact on early, environmental factors on late
neonatal mortality, (3) the explanation model 'gender preferences' is oversimplified as
it applies only to a certain group
Measures to motivate and enable researchers to increase sex/gender sensitivity should focus on aspects of the study design and the statistical analysis, e.g. sex/gender sensitive selection of determinants and outcomes, operationalisation of sex/gender aspects, and power calculation.
Next steps in the analysis of sex/gender sensitivity in epidemiological research would include the coverage of a broader range of epidemiological journals extracting both positive examples as well as examples of sex/gender bias. This should also include an assessment of the consistency and conceptual clarity of the terms sex and gender [96]. 


\section{What is already known?}

- Epidemiological research is often of limited significance in terms of sex/gender sensitivity.

- There is a growing body of knowledge concerning the analysis and avoidance of sex/gender bias.

\section{What this paper adds?}

This paper serves as a first step to use positive examples in order to develop and disseminate sex/gender sensitive research and provides indications on how to practically implement sex/gender aspects.

\section{Additional file}

Additional file 1: Assessment instrument: Identification of good practice examples of sex/gender sensitive health research. (PDF $48 \mathrm{~kb}$ )

\section{Abbreviations}

JECH: Journal of Epidemiology and Community Health

\section{Acknowledgments}

We thank the scientific board of the project 'Epi goes Gender' and our colleagues Johann Frick, Dirk Gansefort, Hannah Jilani, Ina Schaefer, as well as Florence Samkange-Zeeb, Ronja Foraita, Iris Pigeot, and Hajo Zeeb for valuable comments on earlier versions of this paper. Additionally, we thank Gabriele Bolte, Enno Swart and Hajo Zeeb for their comments on the assessment instrument.

\section{Funding}

This research was conducted as part of the network "Gender-sensitive Research in Epidemiology, Neurosciences and Genetics/Tumour Research" [Sub-Project: Epi goes Gender]. The authors gratefully acknowledge the financial support of the German Federal Ministry of Education and Research (BMBF) (grant no. 01FP1058/59) and of the European Social Fund of the European Union (ESF). The responsibility for the content of this publication lies with the authors. The publication of this article was funded by the Open Access Fund of the Leibniz Association.

\section{Availability of data and materials}

All relevant data are within the text and additional files. For further information please contact the authors.

\section{Authors' contributions}

IJ planned the study with contributions of CB and FG. IJ, CB and FG developed the assessment instrument and evaluated the articles. IJ and TB drafted the manuscript with contributions from CB and FG. All authors critically reviewed the drafts and approved the final version of this manuscript for submission.

\section{Competing interests}

The authors declare that they have no competing interests.

\section{Consent for publication}

Not applicable.

\section{Ethics approval and consent to participate} Not applicable.

\section{Author details}

'Department Prevention and Evaluation, Leibniz Institute for Prevention Research and Epidemiology - BIPS, Achterstr. 30, 28359 Bremen, Germany. ${ }^{2}$ Department Biometry and Data Management, Leibniz Institute for Prevention Research and Epidemiology - BIPS, Achterstr. 30, 28359 Bremen, Germany.
Received: 5 September 2016 Accepted: 30 January 2017

Published online: 15 February 2017

\section{References}

1. Beery AK, Zucker I. Sex bias in neuroscience and biomedical research. Neurosci Biobehav Rev. 2011;35:565-72. doi:10.1016/j.neubiorev.2010.07.002.

2. Gelb K, Pederson A, Greaves L. How have health promotion frameworks considered gender? Health Promot Int. 2012;27:445-52. doi:10.1093/ heapro/dar087.

3. Zahm SH, Pottern LM, Lewis DR, Ward MH, White DW. Inclusion of women and minorities in occupational cancer epidemiologic research. J Occup Environ Med. 1994;36:842-7.

4. Stephenson P, McKee M. Look twice. Eur J Public Health. 1993;3:151-2.

5. Hohenadel K, Raj P, Demers PA, Zahm SH, Blair A. The inclusion of women in studies of occupational cancer: a review of the epidemiologic literature from 1991-2009. Am J Ind Med. 2015;58:276-81. doi:10.1002/ajim.22424.

6. Mazure CM, Jones DP. Twenty years and still counting: including women as participants and studying sex and gender in biomedical research. BMC Womens Health. 2015;15:94. doi:10.1186/s12905-015-0251-9.

7. Bolte G. Gender in epidemiology. State of discussion and perspectives. Bundesgesundheitsblatt Gesundheitsforschung Gesundheitsschutz. 2008;51: 3-12. doi:10.1007/s00103-008-0414-z.

8. Garcia-Calvente Mdel M, Ruiz-Cantero MT, Del Rio-Lozano M, Borrell C, Lopez-Sancho MP. Gender inequalities in research in public health and epidemiology in Spain (2007-2014). Gac Sanit. 2015;29:404-11. doi:10.1016/j. gaceta.2015.07.013.

9. Ovseiko PV, Greenhalgh T, Adam P, Grant J, Hinrichs-Krapels S, Graham KE, Valentine PA, Sued O, Boukhris OF, Al Olaqi NM, et al. A global call for action to include gender in research impact assessment. Health Res Policy Syst. 2016;14:50. doi:10.1186/s12961-016-0126-z.

10. Sex and Gender-Based Analysis - Health Canada. http://www.hc-sc.gc.ca/hlvs/gender-genre/analys/index-eng.php. Accessed 1 April 2016.

11. Nonsexist EM, Methods R. A practical guide. Boston: Allen and Unwin; 1988

12. Eichler M. Nonsexist Research Methods. A Practical Guide. Hoboken: Taylor and Francis; 2013. Online-Resource.

13. Ruiz MT, Verbrugge LM. A two way view of gender bias in medicine. J Epidemiol Community Health. 1997;51:106-9.

14. Ruiz-Cantero MT, Vives-Cases C, Artazcoz L, Delgado A, Garcia Calvente MM, Miqueo C, Montero I, Ortiz R, Ronda E, Ruiz I, Valls C. A framework to analyse gender bias in epidemiological research. J Epidemiol Community Health. 2007;61:ii46-53. doi:10.1136/jech.2007.062034.

15. Gahagan J, Gray K, Whynacht A. Sex and gender matter in health research: addressing health inequities in health research reporting. Int J Equity Health. 2015;14:12. doi:10.1186/s12939-015-0144-4.

16. Hammarström A, Annandale E. A conceptual muddle: an empirical analysis of the use of 'sex' and 'gender' in 'gender-specific medicine' journals. PLoS One. 2012;7:e34193. doi:10.1371/journal.pone.0034193.

17. Ritz SA, Antle DM, Cote J, Deroy K, Fraleigh N, Messing K, Parent L, St-Pierre J, Vaillancourt C, Mergler D. First steps for integrating sex and gender considerations into basic experimental biomedical research. FASEB J. 2014 28:4-13. doi:10.1096/fj.13-233395

18. Westbrook L, Saperstein A. New categories are not enough rethinking the measurement of sex and gender in social surveys. Gender Soc. 2015;29:534-60.

19. Clayton J, Tannenbaum C. Reporting sex, gender, or both in clinical research? JAMA. 2016;316:1863-4. doi:10.1001/jama.2016.16405.

20. Fausto-Sterling A. The bare bones of sex: part 1 - sex and gender. Signs. 2005;30:1491-527.

21. Short SE, Yang YC, Jenkins TM. Sex, gender, genetics, and health. Am J Public Health. 2013;103 Suppl 1:S93-S101. doi:10.2105/AJPH.2013.301229.

22. Springer KW, Mager Stellman J, Jordan-Young RM. Beyond a catalogue of differences: a theoretical frame and good practice guidelines for researching sex/gender in human health. Soc Sci Med. 2012;74:1817-24. doi: 10.1016/j.socscimed.2011.05.033.

23. Doyal L. Sex and gender: the challenges for epidemiologists. Int J Health Serv. 2003:33:569-79.

24. White A, Richardson N. Gendered epidemiology: making men's health visible in epidemiological research. Public Health. 2011;125:407-10. doi:10. 1016/j.puhe.2011.04.012

25. Krieger N. Genders, sexes, and health: what are the connections-and why does it matter? Int J Epidemiol. 2003;32:652-7. doi:10.1093/ije/dyg156. 
26. Fishman JR, Wick JG, Koenig BA. The use of "sex" and "gender" to define and characterize meaningful differences between men and women. Agenda for research on women's health for the 21 st century. Washington: Department of Health and Human Services; 1999.

27. Krieger N, Fee E. Man-made medicine and women's health: the biopolitics of sex/gender and race/ethnicity. Int J Health Serv. 1994;24:265-83.

28. Doull M, Welch V, Puil L, Runnels V, Coen SE, Shea B, O'Neill J, Borkhoff C, Tudiver S, Boscoe M. Development and evaluation of 'briefing notes' as a novel knowledge translation tool to aid the implementation of sex/gender analysis in systematic reviews: a pilot study. PLoS One. 2014;9:e110786. doi: 10.1371/journal.pone.0110786.

29. Runnels V, Tudiver S, Doull M, Boscoe M. The challenges of including sex/ gender analysis in systematic reviews: a qualitative survey. Syst Rev. 2014;3: 33. doi:10.1186/2046-4053-3-33

30. Jordan-Young R, Rumiati RI. Hardwired for sexism? Approaches to sex/gender in neuroscience. Neuroethics. 2012;5:305-15. doi:10.1007/s12152-011-9134-4.

31. Garcia AM, Bartley M, Alvarez-Dardet C. Engendering epidemiology. J Epidemiol Community Health. 2007;61:ii1-2. doi:10.1136/jech.2007.069658.

32. Moerman CJ, van Mens-Verhulst J. Gender-sensitive epidemiological research: suggestions for a gender-sensitive approach towards problem definition, data collection and analysis in epidemiological research. Psychol Health Med. 2004;9:41-52. doi:10.1080/13548500310001637742.

33. Artazcoz L, Borrell C, Cortes I, Escriba-Aguir V, Cascant L. Occupational epidemiology and work related inequalities in health: a gender perspective for two complementary approaches to work and health research. J Epidemiol Community Health. 2007;61:ii39-45. doi:10.1136/jech.2007.059774.

34. Nieuwenhoven L, Klinge I. Scientific excellence in applying sex- and gendersensitive methods in biomedical and health research. J Womens Health (Larchmt). 2010;19:313-21. doi:10.1089/jwh.2008.1156.

35. Clougherty JE. A growing role for gender analysis in air pollution epidemiology. Cien Saude Colet. 2011;16:2221-38.

36. Jahn I, Gansefort D, Kindler-Röhrborn A, Pfleiderer B. Sex- and gendersensitive research in epidemiology and medicine: how can this be achieved? Aims and first results of the network "Sex-/Gender-Sensitive Research in Epidemiology, Neurosciences and Genetics/Cancer Research". Bundesgesundheitsblatt Gesundheitsforschung Gesundheitsschutz. 2014;57: 1038-46. doi:10.1007/s00103-014-2010-8.

37. Jahn I. Methodische Probleme einer geschlechtergerechten Gesundheitsforschung. In: Kolip P, Hurrelmann K, editors. Handbuch Geschlecht und Gesundheit Männer und Frauen im Vergleich, vollst. überarb. und erw. Aufl. 2nd ed. Bern: Hogrefe; 2016. p. 71-86.

38. European Commission. Fact Sheet: Gender Equality in Horizon 2020. 2013. https://ec.europa.eu/programmes/horizon2020/sites/horizon2020/files/ FactSheet_Gender_2.pdf. Accessed 14 Jun 2016.

39. Heidari S, Babor TF, De Castro P, Tort S, Curno M. Sex and gender equity in research: rationale for the SAGER guidelines and recommended use. Res Integr Peer Rev. 2016;1:1-9. doi:10.1186/s41073-016-0007-6.

40. Hammarström A, Johansson K, Annandale E, Ahlgren C, Aléx L, Christianson M, Elwér S, Eriksson C, Fjellman-Wiklund A, Gilenstam K. Central gender theoretical concepts in health research: the state of the art. J Epidemiol Community Health. 2014;68:185-90.

41. Jiménez-Rodrigo ML, Martínez-Morante E, del Mar G-CM, Álvarez-Dardet C. Through gender parity in scientific publications. J Epidemiol Community Health. 2008;62:474-5.

42. Phillips SP. Measuring the health effects of gender. J Epidemiol Community Health. 2008;62:368-71. doi:10.1136/jech.2007.062158.

43. Eichler M, Fuchs J, Maschewsky-Schneider U. Richtlinien zur Vermeidung von Gender Bias in der Gesundheitsforschung. Zeitschrift für Gesundheitswissenschaften. 2000;8:293-310.

44. Phillips SP. Defining and measuring gender: a social determinant of health whose time has come. Int J Equity Health. 2005:4:11.

45. Kennedy SM, Koehoorn M. Exposure assessment in epidemiology: does gender matter? Am J Ind Med. 2003:44:576-83.

46. Singh S, Klinge I. Mining for methods - A critical review of the theoretical and methodological contributions of feminist science scholars for biomedicine and public health research. Zeitschrift für Geschlechterstudien. 2015;21:15-31.

47. Kunkel SR, Atchley RC. Why gender matters: being female is not the same as not being male. Am J Prev Med. 1996;12:294.

48. Jahn I, Foraita R. Geschlechtergerechte epidemiologische Datenanalyse: Methodische Aspekte und empirische Befunde. Bundesgesundheitsblatt Gesundheitsforschung Gesundheitsschutz. 2008;51:13-27.
49. Hammarström A. A tool for developing gender research in medicine: examples from the medical literature on work life. Gend Med. 2007;4:S123-32.

50. Bambra C, Pope D, Swami V, Stanistreet D, Roskam A, Kunst A, Scott-Samuel A. Gender, health inequalities and welfare state regimes: a cross-national study of 13 European countries. J Epidemiol Community Health. 2009;63: 38-44. doi:10.1136/jech.2007.070292.

51. Berntsson L, Lundberg U, Krantz G. Gender differences in work-home interplay and symptom perception among Swedish white-collar employees. J Epidemiol Community Health. 2006;60:1070-6. doi:10.1136/jech.2005.042192.

52. Boone-Heinonen J, Gordon-Larsen P. Life stage and sex specificity in relationships between the built and socioeconomic environments and physical activity. J Epidemiol Community Health. 2011;65:847-52. doi:10. 1136/jech.2009.105064

53. Borrell C, Muntaner C, Sola J, Artazcoz L, Puigpinos R, Benach J, Noh S. Immigration and self-reported health status by social class and gender: the importance of material deprivation, work organisation and household labour. J Epidemiol Community Health. 2008;62:e7.

54. Escribà-Agüir V, Gonzalez-Galarzo MC, Barona-Vilar C, Artazcoz L. Factors related to depression during pregnancy: are there gender differences? J Epidemiol Community Health. 2008;62:410-4. doi:10.1136/jech.2007.063016.

55. Escribà-Agüir $\vee$, Artazcoz L. Gender differences in postpartum depression: a longitudinal cohort study. J Epidemiol Community Health. 2011;65:320-6. doi:10.1136/jech.2008.085894.

56. Gissler M, Rahkonen O, Mortensen L, Arntzen A, Cnattingius S, Nybo Andersen AM, Hemminki E. Sex differences in child and adolescent mortality by parental education in the Nordic countries. J Epidemiol Community Health. 2012;66:57-63. doi:10.1136/jech.2009.093153.

57. Haukenes I, Riise T, Haug K, Farbu E, Maeland JG. Smokers' increased risk for disability pension: social confounding or health-mediated effects? Genderspecific analyses of the Hordaland Health Study cohort. J Epidemiol Community Health. 2013;67:758-64. doi:10.1136/jech-2012-202182.

58. Harryson L, Novo M, Hammarström A. Is gender inequality in the domestic sphere associated with psychological distress among women and men? Results from the Northern Swedish Cohort. J Epidemiol Community Health. 2012;66:271-6. doi:10.1136/jech.2010.109231.

59. Hernandez DC, Pressler E. Accumulation of childhood poverty on young adult overweight or obese status: race/ethnicity and gender disparities. J Epidemiol Community Health. 2014;68:478-84. doi:10.1136/jech-2013-203062.

60. Heys M, Jiang C, Cheng KK, Zhang W, Lam TH, Leung GM, Schooling CM. Does childhood meat eating contribute to sex differences in risk factors for ischaemic heart disease in a developing population? J Epidemiol Community Health. 2011;65:522-8. doi:10.1136/jech.2009.099143.

61. Hollander AC, Bruce D, Ekberg J, Burstrom B, Ekblad S. Hospitalisation for depressive disorder following unemployment - differentials by gender and immigrant status: a population-based cohort study in Sweden. J Epidemiol Community Health. 2013;67:875-81. doi:10.1136/jech-2013-202701.

62. Ikeda A, Kawachi I, Iso H, Inoue M, Tsugane S. Gender difference in the association between social support and metabolic syndrome in Japan: the 'enkai' effect? J Epidemiol Community Health. 2011;65:71-7. doi:10.1136/ jech.2009.090613.

63. Kavanagh AM, Bentley R, Turrell G, Broom DH, Subramanian SV. Does gender modify associations between self rated health and the social and economic characteristics of local environments? J Epidemiol Community Health. 2006;60:490-5. doi:10.1136/jech.2005.043562.

64. King WD, Minor $P$, Ramirez Kitchen C, Ore LE, Shoptaw S, Victorianne GD, Rust G. Racial, gender and geographic disparities of antiretroviral treatment among US Medicaid enrolees in 1998. J Epidemiol Community Health. 2008; 62:798-803. doi:10.1136/jech.2005.045567.

65. Kolarcik P, Geckova AM, Orosova O, van Dijk JP, Reijneveld SA. Predictors of health-endangering behaviour among Roma and non-Roma adolescents in Slovakia by gender. J Epidemiol Community Health. 2010;64:1043-8. doi:10. 1136/jech.2009.092098.

66. Kovess-Masfety V, Boyd A, van de Velde S, de Graaf R, Vilagut G, Haro JM, Florescu S, O'Neill S, Weinberg L, Alonso J. Are there gender differences in service use for mental disorders across countries in the European Union? Results from the EU-World Mental Health survey. J Epidemiol Community Health. 2014;68:649-56. doi:10.1136/jech-2013-202962.

67. Mansdotter A, Lindholm L, Lundberg M, Winkvist A, Ohman A. Parental share in public and domestic spheres: a population study on gender equality, death, and sickness. J Epidemiol Community Health. 2006;60: 616-20. doi:10.1136/jech.2005.041327. 
68. Matheson Fl, White HL, Moineddin R, Dunn JR, Glazier RH. Neighbourhood chronic stress and gender inequalities in hypertension among Canadian adults: a multilevel analysis. J Epidemiol Community Health. 2010;64:705-13. doi:10.1136/jech.2008.083303.

69. Matheson Fl, White HL, Moineddin R, Dunn JR, Glazier RH. Drinking in context: the influence of gender and neighbourhood deprivation on alcohol consumption. J Epidemiol Community Health. 2012;66:e4. doi:10. 1136/jech.2010.112441.

70. Matheson Fl, Smith $\mathrm{KL}$, Moineddin R, Dunn JR, Glazier RH. Mental health status and gender as risk factors for onset of physical illness over 10 years. J Epidemiol Community Health. 2014;68:64-70. doi:10. 1136/jech-2013-202838.

71. Matheson Fl, Smith KL, Fazli GS, Moineddin R, Dunn JR, Glazier RH. Physica health and gender as risk factors for usage of services for mental illness. J Epidemiol Community Health. 2014;68:971-8. doi:10.1136/jech-2014-203844.

72. McCormack GR, Friedenreich C, Shiell A, Giles-Corti B, Doyle-Baker PK. Sexand age-specific seasonal variations in physical activity among adults. J Epidemiol Community Health. 2010;64:1010-6. doi:10.1136/jech.2009.092841.

73. Milner A, Page A, LaMontagne AD. Duration of unemployment and suicide in Australia over the period 1985-2006: an ecological investigation by sex and age during rising versus declining national unemployment rates. J Epidemiol Community Health. 2013;67:237-44. doi:10.1136/jech-2012-201594.

74. Mindell JS, Knott CS, Ng Fat LS, Roth MA, Manor O, Soskolne V, Daoud N. Explanatory factors for health inequalities across different ethnic and gender groups: data from a national survey in England. J Epidemiol Community Health. 2014;68:1133-44. doi:10.1136/jech-2014-203927.

75. Nante N, Messina G, Cecchini M, Bertetto O, Moirano F, McKee M. Sex differences in use of interventional cardiology persist after risk adjustment. J Epidemiol Community Health. 2009;63:203-8. doi:10.1136/jech.2008.077537.

76. Niclasen J, Nybo Andersen AM, Teasdale TW, Strandberg-Larsen K. Prenatal exposure to alcohol, and gender differences on child mental health at age seven years. J Epidemiol Community Health. 2014;68:224-32. doi:10.1136/ jech-2013-202956.

77. Pitel L, Madarasova Geckova A, Kolarcik P, Halama P, Reijneveld SA, van Dijk JP. Gender differences in the relationship between religiosity and healthrelated behaviour among adolescents. J Epidemiol Community Health. 2012;66:1122-8. doi:10.1136/jech-2011-200914.

78. Ratner PA, Tzianetas R, Tu AW, Johnson JL, Mackay M, Buller CE, Rowlands $M$, Reime B. Myocardial infarction symptom recognition by the lay public: the role of gender and ethnicity. J Epidemiol Community Health. 2006;60: 606-15. doi:10.1136/jech.2005.037952.

79. Regidor E, de Mateo S, Ronda E, Sanchez-Paya J, Gutierrez-Fisac JL, de la Fuente L, Pascual C. Heterogeneous trend in smoking prevalence by sex and age group following the implementation of a national smoke-free law. J Epidemiol Community Health. 2011;65:702-8. doi:10.1136/jech.2009.091181.

80. Rigby JE, Dorling D. Mortality in relation to sex in the affluent world. J Epidemiol Community Health. 2007;61:159-64. doi:10.1136/jech.2006.047381.

81. Rosenstock S, Katz J, Mullany LC, Khatry SK, LeClerq SC, Darmstadt GL, Tielsch JM. Sex differences in neonatal mortality in Sarlahi, Nepal: the role of biology and environment. J Epidemiol Community Health. 2013;67:986-91. doi:10.1136/jech-2013-202646.

82. Ruiz-Cantero MT, Ronda E, Alvarez-Dardet C. The importance of study design strategies in gender bias research: the case of respiratory disease management in primary care. J Epidemiol Community Health. 2007;61:ii116. doi:10.1136/jech.2007.060301.

83. Staehelin K, Schindler C, Spoerri A, Zemp SE. Marital status, living arrangement and mortality: does the association vary by gender? J Epidemiol Community Health. 2012;66:e22. doi:10.1136/jech.2010.128397.

84. Strand BH, Murray ET, Guralnik J, Hardy R, Kuh D. Childhood social class and adult adiposity and blood-pressure trajectories 36-53 years: gender-specific results from a British birth cohort. J Epidemiol Community Health. 2012;66: 512-8. doi:10.1136/jech.2010.115220.

85. Värnik A, Kolves K, van der Feltz-Cornelis CM, Marusic A, Oskarsson H, Palmer A, Reisch T, Scheerder G, Arensman E, Aromaa E, et al. Suicide methods in Europe: a gender-specific analysis of countries participating in the "European Alliance Against Depression". J Epidemiol Community Health. 2008;62:545-51. doi:10.1136/jech.2007.065391.

86. Vigna-Taglianti F, Vadrucci S, Faggiano F, Burkhart G, Siliquini R, Galanti MR. Is universal prevention against youths' substance misuse really universal? Gender-specific effects in the EU-Dap school-based prevention trial. J Epidemiol Community Health. 2009;63:722-8. doi:10.1136/jech.2008.081513.
87. European Commission. Research \& Innovation. http://ec.europa.eu/research/ swafs/gendered-innovations/index_en.cfm?pg=home. Accessed June 132016.

88. European Commission. Gendered Innovations - How Gender Analysis Contributes to Research. Luxembourg: Publications Office of the European Union; 2013. p. 137

89. European Association of Science Editors. EASE Toolkit for Authors: Sex and Gender Questions. 2015. http://www.ease.org.uk/publications/sex-andgender-questions/. Accessed Aug 172016.

90. European Commission. Research and Innovation. Gendered Innovations in Science, Health \& Medicine, Engineering and Environment. Health and Medicine Checklist. http://ec.europa.eu/research/swafs/genderedinnovations/index_en.cfm?pg=home. Accessed 11 Jan 2017.

91. Day S, Mason R, Lagosky S, Rochon PA. Integrating and evaluating sex and gender in health research. Health Res Policy Syst. 2016;14:75. doi:10.1186/ s12961-016-0147-7.

92. Doull M, Runnels VE, Tudiver S, Boscoe M. Appraising the evidence: applying sex- and gender-based analysis (SGBA) to Cochrane systematic reviews on cardiovascular diseases. J Womens Health (Larchmt). 2010;19(5): 997-1003. doi:10.1089/jwh.2009.1626.

93. European Commission. DG for Research and Innovation. Toolkit Gender in EU-funded Research. 2011. http://bookshop.europa.eu/en/toolkit-gender-ineufunded-research-pbKINA24840/. Accessed 11 Jan 2017.

94. Jahn I, Frick J, Gansefort D. Assessing sex/gender sensitivity of epidemiological publications: development of a screening tool. Eur J Epidemiol. 2013;28:39.

95. Pederson A, Greaves L, Poole N. Gender-transformative health promotion for women: a framework for action. Health Promot Int. 2015;30:140-50. doi: 10.1093/heapro/dau083.

96. Schiebinger $L$, Leopold SS, Miller VM. Editorial policies for sex and gender analysis. Lancet. 2016;388:2841-2. doi:10.1016/s0140-6736(16)32392-3.

\section{Submit your next manuscript to BioMed Central and we will help you at every step:}

- We accept pre-submission inquiries

- Our selector tool helps you to find the most relevant journal

- We provide round the clock customer support

- Convenient online submission

- Thorough peer review

- Inclusion in PubMed and all major indexing services

- Maximum visibility for your research

Submit your manuscript at www.biomedcentral.com/submit
C Biomed Central 